\title{
Utility of CD10 in Distinguishing between Endometrial Stromal Sarcoma and Uterine Smooth Muscle Tumors: An Immunohistochemical Comparison of 34 Cases
}

Peiguo G. Chu, M.D., Ph.D., Daniel A. Arber, M.D., Lawrence M. Weiss, M.D., Karen L. Chang, M.D. Division of Pathology, City of Hope National Medical Center, Duarte, California

Endometrial stromal sarcoma (ESS), uterine cellular leiomyoma (UCL), and uterine leiomyosarcoma (ULS) are composed mainly of spindle cells that express similar antigens such as desmin, smooth muscle actin (SMA), and muscle-specific actin (MSA). The differential diagnosis of an ESS versus a uterine smooth muscle tumor or an extrauterine spindle cell sarcoma can be problematic based solely on clinical presentation, histologic assessment, or routine immunohistochemistry. Recently, we reported that normal endometrium, but not myometrium, as well as five cases of ESS, were positive for CD10. We now report the results of CD10 immunohistochemistry in an additional 11 cases of ESS (total 16 cases), 10 cases of UCL, and nine cases of ULS. CD10 immunoreactivity was detected in 16 of 16 cases of ESS $(100 \%)$ as compared to only 2 of 10 cases of UCL (20\%) and none of nine cases of ULS $(0 \%)$. We compared the utility of CD10 immunoreactivity with that of desmin, SMA, MSA, estrogen receptor (ER), and inhibin in these tumors. Although the majority of cases of UCL and ULS were positive for SMA, MSA, and desmin, a substantial portion of cases of ESS were also positive for SMA, MSA, and desmin. We conclude that in combination with SMA, MSA, and desmin, CD10 is a useful immunohistochemical marker in the differential diagnosis of ESS versus UCL or ULS.

KEY WORDS: CD10, Endometrial stromal sarcoma, Immunohistochemistry, Uterine cellular leiomyoma, Uterine leiomyosarcoma.

Mod Pathol 2001;14(5):465-471

Copyright $\odot 2001$ by The United States and Canadian Academy of Pathology, Inc

VOL. 14, NO. 5, P. 465, 2001 Printed in the U.S.A.

Date of acceptance: December 15, 2000.

Address reprint requests to: Peiguo G. Chu, M.D., Ph.D., Division of

Pathology, City of Hope National Medical Center, 1500 East Duarte Road,

Duarte, CA 91010; e-mail: pchu@coh.org; fax: 626-301-8145.
Endometrial stromal sarcomas (ESSs) account for 0.2 to $1.5 \%$ of all uterine malignancies (1) and $<10 \%$ of cases of uterine sarcomas (2). ESS is usually composed of uniform cells intimately associated with prominent arterioles, closely recapitulating proliferative endometrial stroma. ESS may be confused with uterine cellular leiomyoma (UCL), uterine leiomyosarcoma (ULS), or other sarcomas, in particular, when ESS is associated with myxoid, epithelioid, and fibrous changes (3); has high histologic grade (4); and metastasizes to extrauterine sites (5). The immunohistochemical profile of ESS may have similarities to UCL and ULS, with expression of muscle-specific actin (MSA), smooth muscle actin (SMA), and desmin, particularly in cases of ESS showing smooth muscle differentiation (6-8). Other immunohistochemical markers, including cytokeratin and estrogen receptors, have also been described in both neoplasms (8-11). The lack of a unique immunohistochemical profile for ESS further hampers diagnostic efforts. Cytogenetic studies have not shown consistent chromosomal abnormalities and thus, their utility in the diagnosis of ESS is limited $(5,12)$.

The common acute lymphoblastic leukemia antigen (CALLA or CD10) was originally found to be expressed on the cell surface of most cases of acute lymphoblastic leukemia $(13,14)$, and was soon found in many other types of leukemias, as well as lymphomas and nonhematopoietic neoplasms (15, 16). CD10 functions as a cell surface enzyme that acts to reduce cellular response to peptide hormones by regulating local peptide concentration (17). Thus, many hormone-sensitive and peptidesensitive cells and their corresponding neoplasms express CD10 antigen (18-21), including normal endometrial stroma and ESS (22-24).

In this study, we examined the utility of CD10 paraffin immunohistochemistry and other musclespecific immunohistochemical markers for differentiating primary or metastatic ESS from UCL and ULS. 


\section{MATERIALS AND METHODS}

\section{Case Selection}

The files of the City of Hope National Medical Center Division of Pathology were searched from 1989 to 1999 for the diagnosis of primary or metastatic ESS, UCL, and ULS. Sixteen cases of ESS (including five previously reported cases; 24), 10 cases of UCL, and eight cases of ULS were identified (Table 1). Of the 16 ESS cases, seven were primary, eight were metastatic, and one (Case 14) was a case of primary extrauterine ESS arising from endometriosis. Of the eight ULS cases, four were primary, and four were metastatic. All metastatic cases had a previous history of ESS or ULS. The age range for ESS was 36 to 74 years old (mean age, 51 years), for UCL, it was 31 to 58 years old (mean age, 47 years), and for ULS, it was 40 to 85 years old (mean age, 57 years). The diagnoses of ESS, UCL, and ULS (Table 1) were made by consensus of three of the authors (DAA, LMW, and KLC) based solely on previously established morphologic criteria (25-28), without access to results of immunohistochemical analysis.

\section{Immunohistochemistry}

All tissues were fixed in $10 \%$ neutral buffered formalin and embedded in paraffin. The antibodies used in this study are listed in Table 2. Paraffin section immunohistochemical studies were performed using the avidin-biotin complex technique, augmented by heat-induced epitope retrieval (HIER) methodology and/or enzyme digestion (29, 30). Immunohistochemical staining was performed on an automated immunohistochemical stainer (TechMate 1000, Ventana Medical System, Tucson, AZ). Briefly, deparaffinized 5- $\mu \mathrm{m}$ sections were rehydrated through a xylene and graded alcohol series. For CD10, desmin, smooth muscle actin, estrogen receptor, and inhibin, the slides were rinsed with tap water for 5 minutes and steamed in $1 \mathrm{~mm}$ EDTA buffer ( $\mathrm{pH}$ 8.0) in a household food steamer (HH90, Black and Decker, Shelton, CT) for 20 minutes at $100^{\circ} \mathrm{C}$. For inhibin, the slides were also digested with trypsin (provided by vendor) for 10 minutes. For muscle-specific actin, the slides were digested with trypsin, without HIER. All staining procedures were then carried out on the automated

TABLE 1. Clinical and Immunohistochemical Features of ESS, UCL, and ULS

\begin{tabular}{|c|c|c|c|c|c|c|c|c|c|}
\hline & $\begin{array}{c}\text { Case } \\
\text { Number }\end{array}$ & Age & Site & CD 10 & Desmin & SMA & MSA & Inhibin & ER \\
\hline \multirow[t]{16}{*}{ ESS } & 1 & 40 & Endometrium & + & + & + & - & - & + \\
\hline & 2 & 47 & Endometrium & + & + & + & + & - & + \\
\hline & 3 & 47 & Endometrium & + & - & + & - & - & + \\
\hline & 4 & 53 & Endometrium & + & + & - & - & - & + \\
\hline & 5 & 48 & Endometrium & + & - & + & + & - & - \\
\hline & 6 & 57 & Endometrium & + & + & + & + & - & + \\
\hline & 7 & 41 & Endometrium & + & + & - & - & - & + \\
\hline & 8 & 55 & Pelvic & + & - & - & - & - & - \\
\hline & 9 & 74 & Abdomen & + & - & + & + & - & - \\
\hline & 10 & 56 & Abdomen & + & + & - & + & - & - \\
\hline & 11 & 62 & Abdomen & + & - & - & - & - & + \\
\hline & 12 & 50 & Bladder & + & - & - & - & - & + \\
\hline & 13 & 42 & Lung & + & - & + & + & - & + \\
\hline & 14 & 36 & Omentum & + & + & - & - & - & + \\
\hline & 15 & 46 & Pelvic & + & - & - & - & - & + \\
\hline & 16 & 65 & Peritoneum & + & + & - & - & - & + \\
\hline \multirow[t]{10}{*}{ UCL } & 17 & 42 & Uterus & + & + & + & + & - & + \\
\hline & 18 & 50 & Uterus & + & + & + & + & - & + \\
\hline & 19 & 77 & Uterus & - & + & + & + & - & + \\
\hline & 20 & 33 & Uterus & - & + & + & + & - & + \\
\hline & 21 & 42 & Uterus & - & + & + & + & - & + \\
\hline & 22 & 40 & Uterus & - & + & + & + & - & + \\
\hline & 23 & 31 & Uterus & - & + & + & + & - & + \\
\hline & 24 & 40 & Uterus & - & + & + & + & - & + \\
\hline & 25 & 54 & Uterus & - & + & + & + & - & + \\
\hline & 26 & 58 & Uterus & - & + & + & + & - & + \\
\hline \multirow[t]{8}{*}{ ULS } & 27 & 61 & Uterus & - & + & + & + & - & - \\
\hline & 28 & 73 & Uterus & - & + & + & + & - & - \\
\hline & 29 & 40 & Uterus & - & + & + & + & - & + \\
\hline & 30 & 52 & Uterus & - & + & + & + & - & + \\
\hline & 31 & 54 & Abdomen & - & + & + & - & - & + \\
\hline & 32 & 47 & Colon & - & - & + & + & - & - \\
\hline & 33 & 44 & Pelvic & - & + & + & - & - & - \\
\hline & 34 & 85 & Pelvic & - & + & + & + & - & + \\
\hline
\end{tabular}

ESS, endometrial stromal sarcoma; UCL, uterine cellular leiomyoma; ULS, uterine leiomyosarcoma; SMA, $\alpha$-smooth muscle actin; MSA, musclespecific actin; ER, estrogen receptor. 
TABLE 2. Antibodies Used in Immunohistochemical Studies

\begin{tabular}{lllll}
\hline $\begin{array}{c}\text { Antibody } \\
\text { Clones }\end{array}$ & Specificity & Dilution & Antigen Retrieval $^{\mathrm{a}}$ & \\
\hline HHF35 & MSA & $1: 50$ & Enzyme & Source \\
56C6 & CD10 & $1: 10$ & HIER & Accurate Chemical \& Scientific Corporation, Westbury, NY \\
D33 & Desmin & $1: 2$ & HIER & Vovocastra, Burlingame, CA \\
ER1D5 & ER & $1: 100$ & HIER & Immunotech, Inc., Westbrook, ME \\
RI & Inhibin & $1: 4$ & HIER \& enzyme & Serotec Ltd., Oxford, England \\
Asm-1 & SMA & Undiluted & HIER & Ventana Medical System, Inc., Tucson, AZ \\
\hline
\end{tabular}

HIER, heat-induced epitope retrieval; ER, estrogen receptor; SMA, $\alpha$-smooth muscle actin; MSA, muscle-specific actin.

${ }^{\text {a }}$ See Materials and Methods.

stainer as previously described (24). Cytoplasmic and membranous immunostaining were evaluated.

\section{RESULTS}

\section{General Features}

The hematoxylin and eosin (H\&E) sections of ESS typically showed uniform tumor cells whorled around arterioles (Fig. 1A). Cases of UCL were characterized by densely cellular fascicles of smooth muscle with little intervening collagen, fewer than five mitotic figures per 10 high-power field, and little or no cytologic atypia $(28,31)$. Cases of ULS were highly cellular tumors composed predominantly of intersecting bundles of large spindled cells with markedly atypical nuclei, increased mitotic figures, and frequent atypical mitotic figures (Fig. 1C).

\section{Immunohistochemical Results}

The results of immunohistochemical studies are summarized in Table 1 . The majority of cases of ESS were $\mathrm{CD}_{10}{ }^{+}, \mathrm{ER}^{-1+}, \mathrm{SMA}^{-1+}$, and $\mathrm{MSA}^{-1+}$, whereas the majority of cases of UCL and ULS were $\mathrm{CD} 10^{-}, \mathrm{ER}^{-1+}, \mathrm{SMA}^{+}$, and $\mathrm{MSA}^{+}$.
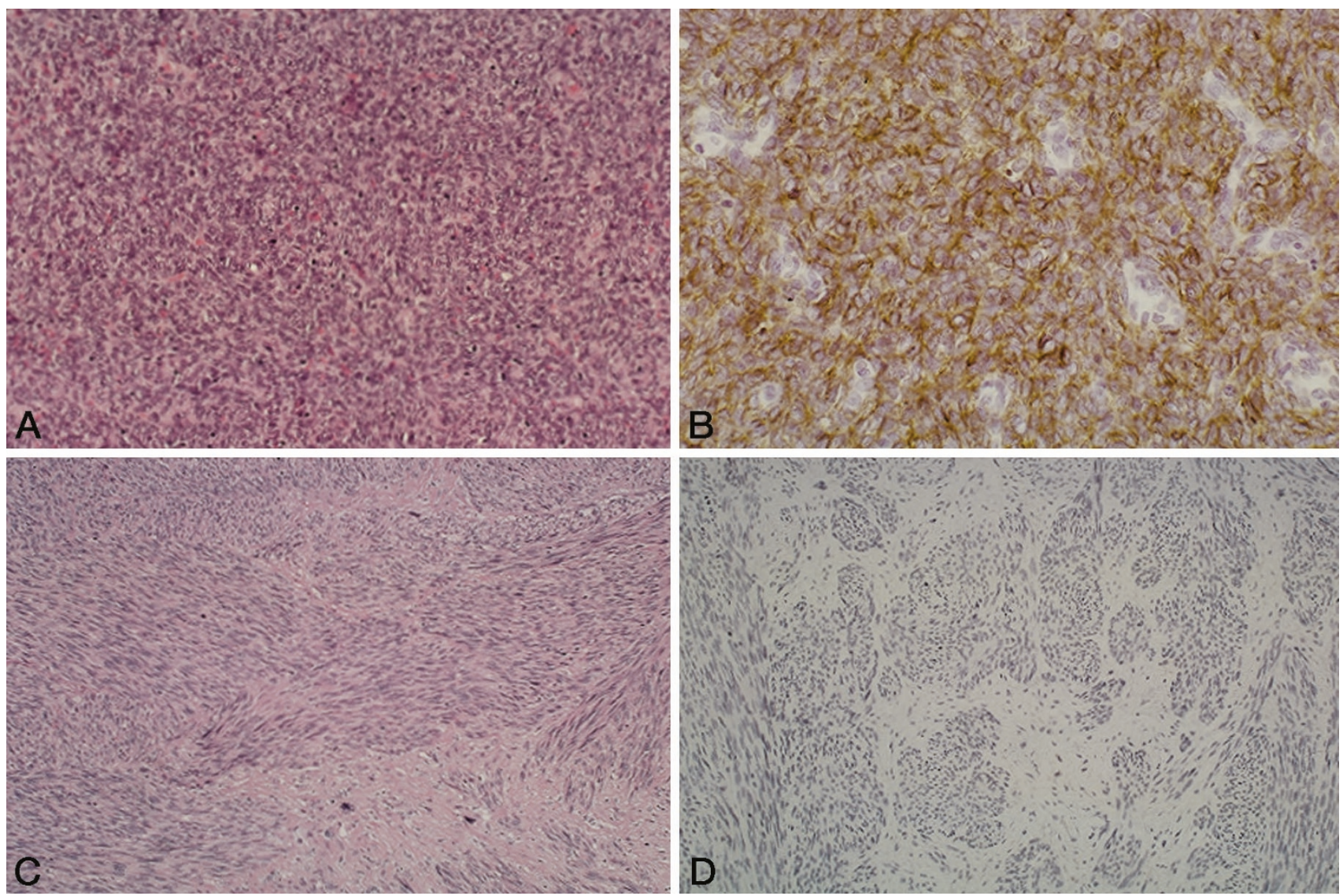

FIGURE 1. Endometrial stromal sarcoma (Case 9) shows uniformly sized tumor cells whorling around arterioles on hematoxylin and eosin (H\&E) section (A). Tumor cells are diffusely positive for CD10 by immunohistochemistry, whereas the periarteriolar cells are negative (B). Uterine leiomyosarcoma (Case 30) shows intersecting bundles of spindled cells with nuclear atypia and atypical mitotic figures on H\&E section (C). Tumor cells are negative for CD10 by immunohistochemistry (D). 


\section{CD10 in ESS}

All 16 cases of ESS (100\%) were positive for CD10. The tumor cells usually showed diffusely membranous and cytoplasmic CD10 positivity, whereas the periarteriolar cells were negative (Fig. 1B). We observed no difference in CD10 staining quantity or intensity among cases of primary, metastatic, or extrauterine ESS. Within any given case, the staining intensity varied, with some tumor cells staining darker than other tumor cells (Fig. 2A). Cases of ESS with myxoid features (Fig. 2B) or with a prominent spindle cell component were also diffusely CD10 positive (Fig. 2C). Many CD10-positive tumor cells coexpressed SMA, MSA, desmin, and ER.

\section{CD10 in UCL}

Two of 10 cases of UCL showed focal $(<5 \%)$ CD10-positivity. The CD10-positive cells were characterized by round or ovoid shape with inconspicuous cytoplasm and were intimately associated with blood vessels (Fig. 3, A-B) on H\&E sections. Typical smooth muscle cells with elongated nuclei were CD10-negative. The interface between the CD10-positive areas and the CD10-negative areas was not well demarcated.

\section{CD10 in ULS}

All eight cases of ULS did not stain for CD10 (0\%) (Fig. 1D).

Expression of SMA, MSA, Desmin, ER, and Inhibin in ESS, UCL, and ULS

The immunohistochemistry results of SMA, MSA, desmin, ER, and inhibin in ESS, UCL, and ULS are also summarized in Table 1. SMA, MSA, and desmin immunoreactivities were seen in both conventional areas of ESS and areas of ESS showing smooth muscle differentiation. All 10 cases of UCL (100\%) and all eight cases of ULS (100\%) expressed SMA in almost all tumor cells. In contrast, only $7 / 16$ (44\%) ESS cases expressed SMA. Staining was seen diffusely throughout the tumor. MSA was positive in all 10 cases of UCL (100\%), 6/8 cases of ULS (75\%), and $6 / 16$ cases of ESS (37\%). MSA staining was seen in the majority of tumor cells. Desmin was positive in all 10 cases of UCL ( $100 \%), 7 / 8$ cases of ULS $(87 \%)$, and $8 / 16$ cases of ESS $(50 \%)$. Although the majority of cases of ESS, UCL, and ULS showed cytoplasmic desmin positivity, some cases of ESS showed perinuclear dot-like (Golgi pattern) desmin positivity. ER was positive in all 10 cases of UCL (100\%), $4 / 8$ cases of ULS (50\%), and 12 of 16 cases of ESS (75\%). All 34 cases of ESS, UCL, and ULS were negative for inhibin.

\section{DISCUSSION}

Endometrial stromal tumors and uterine smooth muscle tumors represent two major types of uterine mesenchymal tumors. The necessity of distinguishing between the two tumor types often arises in surgical pathology practice. The distinction between endometrial stromal tumors and highly cellular leiomyomas and other cellular spindle cell tumors is important for several reasons $(26,32)$. First, highly cellular leiomyomas can be confused with an endometrial stromal nodule when the former is well circumscribed or with an ESS when the borders of a leiomyoma are irregular (33). It is crucial to differentiate a highly cellular leiomyoma from an ESS because the former always follows a benign clinical course, and the latter is capable of behaving aggressively. Second, cases of metastatic ESS or primary extrauterine ESS should be recognized and separated from other spindled cell tumors because the majority of cases of ESS are ER positive and can be treated with antiestrogen therapy.

In most circumstances, it is not difficult to separate ESS from uterine smooth muscle tumors by routine histologic examination. However, the most difficult differential diagnoses lie between endometrial stromal tumors, highly cellular leiomyomas, and leiomyosarcoma. Immunohistochemistry is not useful in this differential diagnosis for several reasons: there are no endometrial stroma-specific immunohistochemical markers; both endometrium and myometrium derive from the Müllerian duct embryonically and therefore often express identical antigens; and the endometrial stromal cells have myofibroblastic qualities with a potential for differentiation into fully developed smooth muscle cells (34-36). Therefore, endometrial stromal tumors that arise in the endometrial stroma may express muscle-related antigens and vimentin $(6,7,37)$.

SMA, MSA, and vimentin were shown by many researchers to have little reliability in differentiating endometrial stromal neoplasms from uterine smooth-muscle tumors. However, there appeared to be conflicting results regarding the discriminatory value of desmin for this differential diagnosis. Oliva et al. demonstrated that all highly uterine cellular leiomyomas were positive for desmin, whereas endometrial stromal nodules and ESSs were negative (38). In contrast, Farhood et al. (8) found that 7 of 23 ESSs were positive for desmin, including three focally positive $(<30 \%$ cells), three diffusely positive (30 to $70 \%$ cells), and one with generalized positivity ( $>70 \%$ cells). In addition, after studying 10 cases of normal endometrial stromal cells of proliferative or secretory phases and 14 cases of endometrial stromal neoplasms (12 ESSs and two stromal nodules), Franquemont et al. (6) 

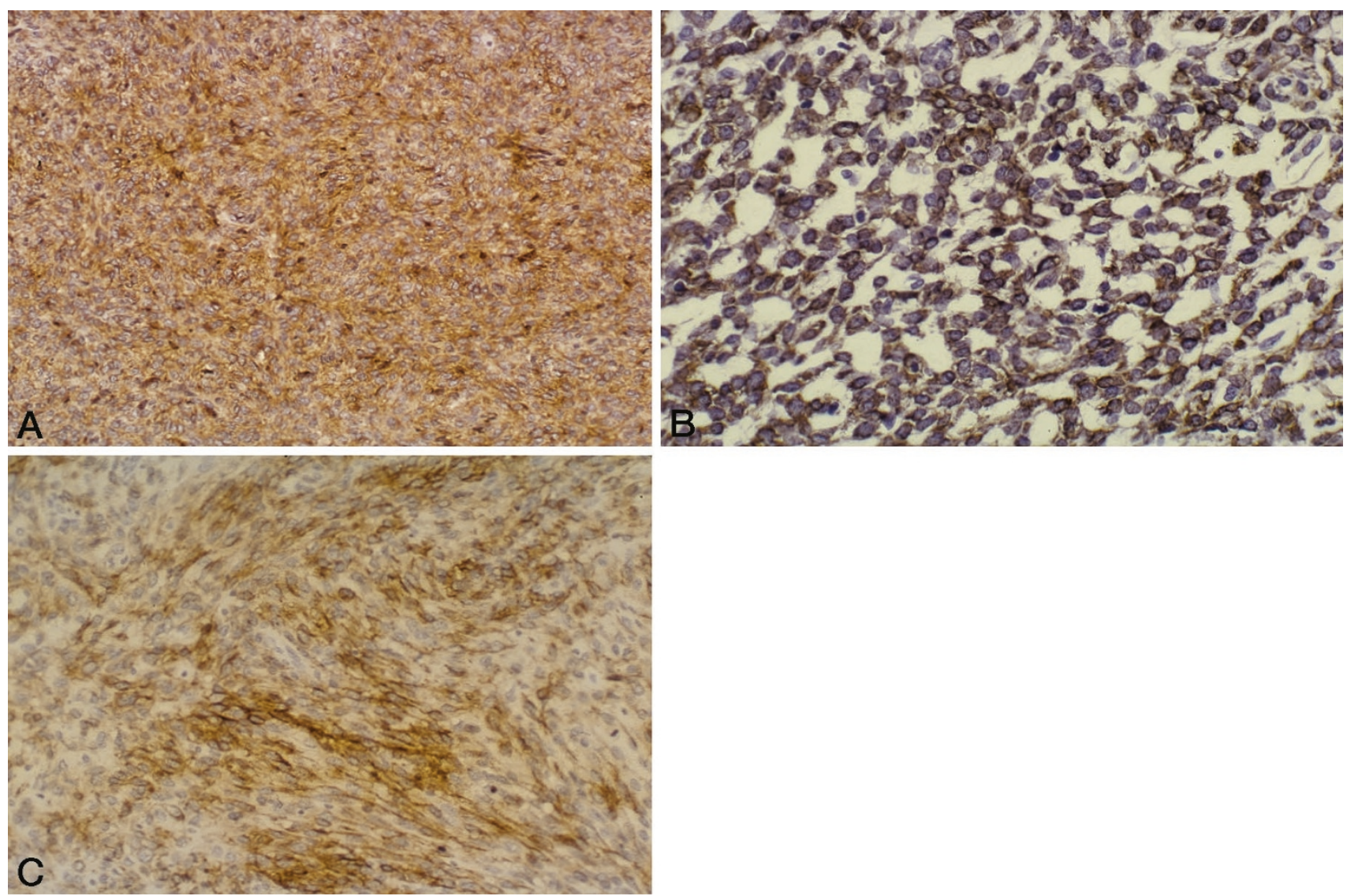

FIGURE 2. Diffuse CD10 immunoreactivity is seen in different histologic variants of ESS: (A) classical (Case 5), (B) myxoid (Case 7), and (C) with prominent spindle cell (Case 1). Note the staining intensity varies between tumor cells in (A).
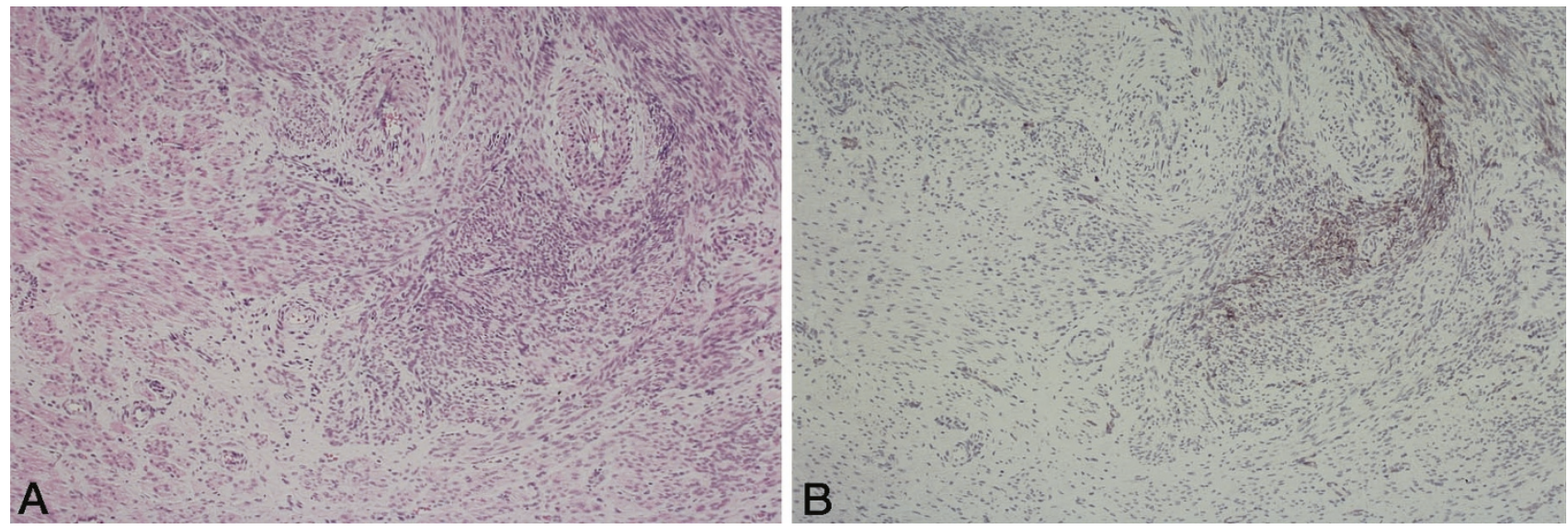

FIGURE 3. Uterine cellular leiomyoma (Case 18) shows intersecting fascicles of smooth muscle cells on hematoxylin and eosin section (A) and focal CD10-positive round, ovoid or spindled cells intimately associated with vessels (B). Both (A) and (B) were photographed from the same field.

identified desmin positivity in nine cases of normal endometrial stromal cells (eight with rare cells staining and one with diffuse staining) and nine cases of endometrial stromal neoplasms (seven ESSs and two stromal nodules). Three of the seven desmin-positive ESSs showed scattered positive cells, whereas four were diffusely positive. Our results also indicate that SMA, MSA, and vimentin were not reliable markers for differentiating ESS from a uterine cellular leiomyoma or uterine leiomyosarcoma. In addition, desmin reactivity in our study did not have high discriminatory value between ESS from UCL or ULS. The different immunohistochemistry staining results may be the result of case selection (some cases may have had more myxoid or epithelioid changes) or the use of different antibody clones. The staining differences among the tumor types were not apparent after use of antigen-retrieval immunohistochemistry methods, which were not used in the three cited reports. 
The value of ER and cytokeratins in the differential diagnosis of ESS versus uterine smooth muscle tumor is limited, because both ESSs and uterine smooth muscle tumors are usually ER positive and occasionally cytokeratin positive $(8,10,11)$. Inhibin was positive only in cases of ESS with sex-cord-like elements, which can be found in 15 to $60 \%$ of ESS (39). In the current study, none of 16 cases of ESS showed sex-cord-like elements. For cases of ESS without sex-cord-like elements, inhibin immunohistochemistry does not provide useful information.

Imai et al. (23) demonstrated CD10-positivity in human endometrial stromal cells and decidual cells, as well as stromal cells of endometriosis and adenomyosis by indirect immunofluorescence staining (40). There have been no follow-up studies on this topic since his two studies. In the current study, we investigated CD10 expression in 16 cases of ESS, 10 cases of UCL, and eight cases of ULS. All 16 cases of ESS were diffusely positive for CD10, whereas all eight cases of ULS and 8 of 10 cases of UCL did not stain for CD10. The two CD10-positive UCLs showed focal scanty positive cells $(<5 \%)$. As outlined earlier, the vast majority of our UCL and ULS cases and over one third of our ESS cases were positive for SMA, MSA, and desmin. These observations indicate that $\mathrm{CD} 10$ protein expression is a relatively specific endometrial stromal marker in the uterus and can be used in differentiating endometrial stromal tumors from uterine smooth muscle tumors.

In the current study, we found that 2 of 10 cases of UCL had scattered clusters of CD10-positive round or ovoid cells with inconspicuous cytoplasm (morphologically different from nearby smooth muscle cells), suggesting endometrial stromal differentiation. The interface between the smooth muscle cells and CD10-positive cells in the two cases was vague, and the volume of CD10-positive cells was small. This is in contrast to the morphologic features of a "mixed endometrial stromal and smooth muscle tumor of the uterus," which is an endometrial stromal tumor with a prominent (>30\%) component of smooth muscle differentiation. In the latter tumor, both components are usually well demarcated from one another. Whether CD10-positive cells in our two UCL cases truly represent a tumor with stromal differentiation or entrapped normal endometrial stroma or gland-poor adenomyosis cannot be determined. However, we did not observe adenomyosis elsewhere in the two CD10-positive UCL cases.

The major clinicopathologic application of CD10 immunoreactivity has been in the diagnosis of precursor B-cell leukemia, follicular lymphoma, and Burkitt-type lymphoma. CD10 paraffin immunohistochemistry is also useful in the differentiating of renal cell carcinoma (where it is often positive) from other carcinomas (where it is often negative; 24). Spindle myoepithelial cells of the breast (41) and spindle stromal cells of the bone marrow (42) have also been found to be CD10 positive. We previously found that vast majority of cases of lowgrade spindle cell sarcomas resembling ESS, such as gastrointestinal stromal tumor, fibrosarcoma, synovial sarcoma, leiomyosarcoma, and schwannoma, were negative for CD10. Only some cases of high-grade peripheral nerve sheath tumor, rhabdomyosarcoma, and leiomyosarcoma with marked pleomorphic features, and some cases of epithelioid sarcoma, were CD10 positive (24).

In summary, we found that diffuse CD10 immunoreactivity is a very useful positive predictive marker for ESS. In particular, CD10 detection is useful in differentiating ESS from UCL and ULS, although rare cases of UCL may show focal CD10 immunoreactivity. The study of more cases of ESS and various types of uterine smooth muscle tumors will be helpful to confirm the utility of CD10 antibody in the differential diagnosis of these tumor types.

\section{REFERENCES}

1. Nordal RR, Kristensen GB, Kaern J, Stenwig AE, Pettersen EO, Trope CG. The prognostic significance of surgery, tumor size, malignancy grade, menopausal status, and DNA ploidy in endometrial stromal sarcoma. Gynecol Oncol 1996;62: 254-9.

2. Hendrickson MR, Kempson RL. Pure mesenchymal neoplasms of the uterine corpus. In: Fox H, editor. Obstetrical and gynecological pathology. New York: Churchill Livingstone; 1995:419-86.

3. Oliva E, Young RH, Clement PB, Scully RE. Myxoid and fibrous endometrial stromal tumors of the uterus: a report of 10 cases. Int J Gynecol Pathol 1999;18:310-9.

4. Evans HL. Endometrial stromal sarcoma and poorly differentiated endometrial sarcoma. Cancer 1982;50:2170-82.

5. Pauwels P, Dal Cin PD, van de Moosdijk CNF, Vrints L, Sciot $\mathrm{R}$, Van den Berghe H. Cytogenetics revealing the diagnosis in a metastatic endometrial stromal sarcoma. Histopathology 1996;29:84-7.

6. Franquemont DW, Frierson HF Jr, Mills SE. An immunohistochemical study of normal endometrial stroma and endometrial neoplasms. Evidence for smooth muscle differentiation. Am J Surg Pathol 1991;15:861-70.

7. Lillemoe TJ, Perrone T, Norris HJ, Dehner LP. Myogenous phenotype of epithelial-like areas in endometrial stromal sarcomas. Arch Pathol Lab Med 1991;115:215-9.

8. Farhood AI, Abrams J. Immunohistochemistry of endometrial stromal sarcoma. Hum Pathol 1991;22:224-30.

9. Binder SW, Nieberg RK, Cheng L, al-Jitawi S. Histologic and immunohistochemical analysis of nine endometrial stromal tumors: an unexpected high frequency of keratin protein positivity. Int J Gynecol Pathol 1991;10:191-7.

10. Navarro D, Cabrera JJ, Leon L, Chirino R, Fernandez L, Lopez A. Endometrial stromal sarcoma expression of estrogen receptors, progesterone receptors and estrogen-induced srp27 (24K) suggests hormone responsiveness. J Steroid Biochem Mol Biol 1992;41:589-96. 
11. Sutton GP, Stehman FB, Michael H, Young PCM, Ehrlich CE. Estrogen and progesterone receptors in uterine sarcomas. Obstet Gynecol 1986;68:709-14.

12. Gil-Benso R, Lopez-Gines C, Carda C, Llombart-Bosch A. Endometrial stromal sarcoma: immunohistochemical, electron microscopical and cytogenetic findings in two cases. Virchows Arch 1999;434:307-14.

13. Greaves MF, Brown G, Rapson NT, Lister TA. Antisera to acute lymphoblastic leukemia cells. Clin Immunol Immunopathol 1975;4:67-84.

14. Greaves MF, Hariri G, Newman RA, Sutherland DR, Ritter MA, Ritz J. Selective expression of the common acute lymphoblastic leukemia (gp100) antigen on immature lymphoid cells and their malignant counterparts. Blood 1983;61:62839.

15. Le Bien TW, McCormack RT. The common acute lymphoblastic leukemia antigen (CD10)_emancipation from a functional enigma. Blood 1989;73:625-35.

16. Arber DA, Weiss LM. CD 10: a review. Appl Immunohistochem 1997;5125-40.

17. Shipp MA, Stefano GB, D'Adamio L, Switzer SN, Howard FD, Sinisterra J, et al. Down regulation of enkephalin-mediated inflammatory response responses by $\mathrm{CD} 10 /$ neutral endopeptidase 24.11. Nature 1990;347:394-6.

18. Gafford JT, Skidgel RA, Erdos EG, Hersh LB. Human kidney "enkephalinase", a neutral metalloendopeptidase that cleaves active peptides. Biochemistry 1983;22:3265-71.

19. Sato $\mathrm{Y}$, Itoh F, Hinoda $\mathrm{Y}$, Ohe $\mathrm{Y}$, Nakagawa N, Ueda R, et al. Expression of CD10/neutral endopeptidase in normal and malignant tissues of the human stomach and colon. J Gastroenterol 1996;31:12-7.

20. Erdos EG, Schulz WW, Gafford JT, Defendini R. Neutral metalloendopeptidase in human male genital tract. Comparison to angiotensin I-converting enzyme. Lab Invest 1985;52:437-47.

21. Avery AK, Beckstead J, Renshaw AA, Corless CL. Use of antibodies to RCC and CD10 in the differential diagnosis of renal neoplasms. Am J Surg Pathol 2000;24:203-10.

22. Imai K, Kanzaki H, Mori T. Cell surface peptides in human endometrium. Mol Hum Reprod 1996;2:425-31.

23. Imai K, Maeda M, Fujiwara H, Okamoto N, Kariya M, Emi N, et al. Human endometrial stromal cells express cluster of differentiation (CD) 13 antigen/aminopeptidase $\mathrm{N}$ and CD10 antigen/neutral endopeptidase. Biol Reprod 1992;46:328-34.

24. Chu PG, Arber DA. Paraffin-section detection of CD10 in 505 non-hematopoietic neoplasms. Frequent expression in renal cell carcinoma and endometrial stromal sarcoma. Am J Clin Pathol 2000;113:374-82.

25. Norris HJ, Taylor HB. Mesenchymal tumors of the uterus. I. Clinical and pathological study of 53 endometrial stromal tumors. Cancer 1966;19:755-66.

26. Chang KL, Crabtree GS, Lim-Tan SKL, Kempson RL, Hendrickson MR. Primary uterine endometrial stromal neoplasms. A clinicopathologic study of 117 cases. Am J Surg Pathol 1990;14:415-38.
27. Longacre TA, Hendrickson MR, Kempson RL. Predicting clinical outcome for the uterine smooth muscle neoplasm with a reasonable degree of certainty. Adv Anat Pathol 1997; 2:95-104.

28. Bell SW, Kempson RL, Hendrickson MR. Problematic uterine smooth muscle neoplasms. A clinicopathologic study of 213 cases. Am J Surg Pathol 1994;18:535-58.

29. Sheibani K, Tubbs RR. Enzyme immunohistochemistry: technical aspects. Semin Diagn Pathol 1984;1235-50.

30. Gown AM, de Wever N, Bottifora H. Microwave-based antigenic unmasking: a revolutionary new technique for routine immunohistochemistry. Appl Immunohistochem 1993;1256-66.

31. Burns B, Curry RH, Bell MEA. Morphologic features of prognostic significance in uterine smooth muscle tumors: a review of 84 cases. Am J Obstet Gynecol 1979;135:109-14.

32. Kempson RL, Hendrickson MR. Pure mesenchymal neoplasms of the uterine corpus: selected problems. Semin Diagn Pathol 1988;5:172-98.

33. Clement PB. The pathology of uterine smooth muscle tumors and mixed endometrial stromal-smooth muscle tumors: a selective review with emphasis on recent advances. Int J Gynecol Pathol 2000;19:39-55.

34. Scully RE. Smooth-muscle differentiation in genital tract disorders. Arch Pathol Lab Med 1981;105:505-7.

35. Fujii S, Konishi I, Mori T. Smooth muscle differentiation at endometrio-myometrial junction. An ultrastructural study. Virchows Arch A Pathol Anat Histopathol 1989;414:105-12.

36. Bird CC, Willis RA. The production of smooth muscle by the endometrial stroma of the adult human uterus. J Pathol Pract 1965;90:75-81.

37. Zaloudek C, Norris HJ. Mesenchymal tumor of the uterus. In: Kurman RJ, editor. Blaustein's pathology of the female genital tract. 4th ed. New York: Spinger-Verlag; 1994:487-528.

38. Oliva E, Young RH, Clement PB, Bhan AK, Scully RE. Cellular benign mesenchymal tumors of the uterus. A comparative morphologic and immunohistochemical analysis of 33 highly cellular leiomyomas and six endometrial stromal nodules, two frequently confused tumors. Am J Surg Pathol 1995;19:757-68.

39. Baker RJ, Hildebrandt H, Rouse RV, Hendrickson MR, Longacre TA. Inhibin and CD99 (MIC2) expression in uterine stromal neoplasms with sex-cord-like elements. Hum Pathol 1999;30:671-9.

40. Imai K, Kanzaki H, Fujiwara H, Kariya M, Okamoto N, Takakura K, et al. Expression of aminopeptidase $\mathrm{N}$ and neutral endopeptidase on the endometrial stromal cells in endometriosis and adenomyosis. Hum Reprod 1992;7:1326-8.

41. Gusterson BA, Monaghan P, Mahendran R, Ellis J, O'Hare MJ. Identification of myoepithelial cells in human and rat breasts by anti-common acute lymphoblastic leukemia antigen antibody A12. J Natl Cancer Inst 1986;77:343-9.

42. Keating A, Whalen CK, Singer JW. Cultured marrow stromal cells express common acute lymphoblastic leukemia antigen (CALLA): implications for marrow transplantation. $\mathrm{Br} \mathrm{J}$ Haematol 1983;55:623-8. 